\title{
EFEITO DO PH E DO AGENTE PRECIPITANTE NAS PROPRIEDADES DO HIDRÓXIDO DE ALUMÍNIO
}

\author{
Aline Beatriz de Almeida da Silva ${ }^{1}$ \\ Ana Carolina Nogueira Nunes ${ }^{2}$ \\ Fernanda Scalfone dos Santos ${ }^{3}$ \\ José Augusto Jorge Rodrigues ${ }^{4}$
}

Resumo: Na catálise heterogênea, a alumina é um dos principais suportes empregados em catalisadores por possuir características específicas tais como, elevadas porosidades e área específica, podendo ser obtida por diversos processos químicos. Neste trabalho, realizou-se a síntese do precursor da alumina empregando como material precursor o aluminato de sódio e como agentes precipitantes o cloreto de alumínio e o ácido clorídrico. Além desses diferentes agentes, estudouse também a influência do pH final do meio reacional, no presente trabalho fixados em 5, 7, 9 e 11. Em função das matérias-primas e do $\mathrm{pH}$ final de síntese do hidróxido de alumínio, obteve-se aluminas com diferentes propriedades morfológicas e texturais.

Palavras-chave: Alumina; Suporte; Catalisador; Agente precipitante; $\mathrm{pH}$.

\footnotetext{
1 Universidade do Vale do Paraíba, Brasil. E-mail: alinebeatriz303@hotmail.com.

2 Universidade do Vale do Paraíba, Brasil. E-mail: anacarol-nogueira@hotmail.com.

${ }^{3}$ Universidade do Vale do Paraíba, Brasil. E-mail: fernanda.scalfone@hotmail.com.

${ }^{4}$ Universidade do Vale do Paraíba, Brasil. E-mail: joseajr@univap.br.
} 